AUTHOR CORRECTION

\title{
Author Correction: Data augmentation in microscopic images for material data mining
}

Boyuan Ma, Xiaoyan Wei, Chuni Liu, Xiaojuan Ban (D), Haiyou Huang (D), Hao Wang, Weihua Xue, Stephen Wu (D), Mingfei Gao, Qing Shen, Michele Mukeshimana, Adnan Omer Abuassba, Haokai Shen and Yanjing Su (DD

npj Computational Materials (2020)6:146; https://doi.org/10.1038/s41524-020-00415-2

Correction to: $n p j$ Computational Materials https://doi.org/10.1038/ s41524-020-00392-6, published online 18 August 2020

The original version of this article omitted the following from the Acknowledgements:

"This work was supported by Beijing Top Discipline for Artificial Intelligent Science and Engineering, University of Science and Technology Beijing".

This has now been corrected in both the PDF and HTML versions of the article.

\begin{abstract}
(i) Open Access This article is licensed under a Creative Commons Attribution 4.0 International License, which permits use, sharing, adaptation, distribution and reproduction in any medium or format, as long as you give appropriate credit to the original author(s) and the source, provide a link to the Creative Commons license, and indicate if changes were made. The images or other third party material in this article are included in the article's Creative Commons license, unless indicated otherwise in a credit line to the material. If material is not included in the article's Creative Commons license and your intended use is not permitted by statutory regulation or exceeds the permitted use, you will need to obtain permission directly from the copyright holder. To view a copy of this license, visit http://creativecommons. org/licenses/by/4.0/.
\end{abstract}

(c) The Author(s) 2020 